\title{
Microsatellite instability in patients with chronic B-cell lymphocytic leukaemia
}

\author{
E Niv ${ }^{* 1,3,4}$, Y Bomstein ${ }^{3}$, M Yuklea ${ }^{2,4}$ and M Lishner ${ }^{1,3,4}$ \\ 'Department of Medicine, Meir Hospital, Kfar-Saba, Israel; '² Department of Hematology, Meir Hospital, Kfar-Saba, Israel; ${ }^{3}$ Department of Oncogenetic \\ Laboratory, Meir Hospital, Kfar-Saba, Israel; ${ }^{4}$ Sackler Faculty of Medicine, Tel-Aviv University, Israel
}

The purpose of our study was to evaluate the microsatellite instability (MSI) at selected loci with known involvement in the oncogenesis of chronic B-cell lymphocytic leukaemia (B-CLL). DNA from B cells (tumour cells) and from T cells (normal controls) of 27 samples of 26 patients with previously untreated B-CLL was extracted. Microsatellite instability in six microsatellite markers was tested using GeneScan Analysis Software. The rate of replication errors positive phenotype (RER +) was determined (MSI in more than $30 \%$ of examined loci). RER + was found in four out of 27 paients (I4.8\%). A larger proportion of patients with stage C B-CLL exhibited RER + than those with stage $A$ or $B(P<0.05)$. A higher prevalence of RER + was demonstrated in a subgroup of patients with additional malignancies (three out of eight patients) in comparison with patients with B-CLL alone $(I / \mid 9)(P=0.03 \mid)$. In conclusion, our study demonstrated that MSI might have a more prominent role in pathogenesis of B-CLL than reported todate. This may result from a selection of microsatellite markers adjacent to chromosomal loci, which are involved in B-cell malignancies, and using GeneScan Analysis Software, which is most modern and precise method of microsatellite analysis.

British Journal of Cancer (2005) 92, I517- 1523. doi:I0.1038/sj.bjc.6602532 www.bjcancer.com

Published online 5 April 2005

(C) 2005 Cancer Research UK

Keywords: microsatellite instability (MSI); loss of heterozygosity (LOH); chronic B-cell lymphocytic leukaemia (B-CLL); replication errors positive phenotype $(R E R+)$

Chronic B-cell lymphocytic leukaemia (B-CLL) is the most common leukaemia in the Western world. It is characterised by the accumulation of long-lived, functionally inactive, mature appearing neoplastic B lymphocytes. Although several studies demonstrated a role of trisomy 12 and structural abnormalities of chromosome $6,11,13$ and 14 in the pathogenesis of B-CLL, the molecular mechanisms involved in this relatively common disease are still poorly understood (Montserrat et al, 1997; Fundia et al, 1998; Dohner et al, 2000). Recently, a possible role of DNA mismatch repair defects and microsatellite instability (MSI) in the pathogenesis of CLL has been debated (Gartenhaus et al, 1996; Pabst et al, 1996; Volpe et al, 1996; Sanz-Vaque et al, 2001).

Microsatellites are short repeat sequences dispersed throughout the genome. They are composed of mono-, di-, tri-, or tetranucleotide repeats. Microsatellites are highly unstable, that is, the number of repeat units tends to change due to slippage errors during DNA replications. These errors are supposedly corrected by DNA repair enzymes, like errors in any different part of the genome. Cells with alteration in DNA mismatch repair enzymes are not able to repair correctly errors during DNA replication, demonstrating RER + (replication errors positive phenotype). Being highly unstable makes microsatellites the best markers of RER + . In other words, while length alterations of microsatellite sequences are usually phenotypically silent, they

\footnotetext{
* Correspondence: Dr E Niv, Department of Medicine, Meir Hospital, Sapir Medical Center, Kfar-Saba, Israel;

E-mail: niv_em@netvision.net.il

Revised 24 January 2005; accepted 28 February 2005; published online 5 April 2005
}

reflect a general defect in the DNA repair mechanism. Comparison of length of microsatellites of malignant cells to that of normal cells enables to find the mutations inside the microsatellites and to determine a malfunction of DNA mismatch repair enzymes. Inactivation of mismatch repair genes and progressive accumulation of replication errors is one of the molecular pathways of oncogenesis.

Microsatellite instability has been found in up to $90 \%$ of tumours of the hereditary nonpolyposis colorectal cancer because of germ-line mutations and further damage to the second allele within the specific mismatch repair genes $h M S H 1, h M L H 2$ and hPMS2 (Peltomaki and Vasen, 1997; Boland et al, 1998). Microsatellite instability is also a distinctive feature in nearly $15-20 \%$ of sporadic colorectal tumours (Peltomaki and Vasen, 1997; Boland et al, 1998; Toft and Arends, 1998; Samowitz et al, 1999; Stone et al, 2000).

Recently, a possible role of abnormalities of DNA repair and MSI in the pathogenesis of haematological malignancies, like Hodgkin's disease, non-Hodgkin's lymphoma, B-cell CLL, Richter's syndrome, hairy cell leukaemia, etc., has been debated (Gartenhaus et al, 1996; Pabst et al, 1996; Randerson et al, 1996; Tasak et al, 1996; Volpe et al, 1996; Mark et al, 1998; Rimsza et al, 2000; Sanz-Vaque et al, 2001). Most previous studies examined genomic instability in a wide variety of genomic loci, which were arbitrarily selected and were known to be unstable in solid tumours. The purpose of our study was to evaluate the instability at microsatellite markers adjacent to chromosomal loci, which are known to be involved in development of B-cell neoplasms, including of B-CLL, or at loci that encode DNA mismatch repair enzymes. 


\section{MATERIALS AND METHODS}

\section{Case selection}

Consecutive patients, with previously untreated B-CLL were recruited from the Department of Hematology of Meir hospital between April 2000 and April 2001. The study group was composed of all newly diagnosed B-CLL patients during $2000-$ 2001 and of previouly untreated patients with known B-CLL, who came to the rutine follow-up visit during this year. B-cell lymphocytic leukaemia was diagnosed according to the standard criteria. Demographic, laboratory, as well as clinical data, were collected. The medical records of all the participants were checked for additional malignancies in the past. Patients who received chemotherapy for other malignancies were excluded. Surgical treatment was not considered as an exclusion criteria.

The study was approved by the local research ethics committee. All patients provided an informed consent.

\section{DNA collection and processing}

Peripheral blood samples were collected from the patients with CLL and mononuclear cells were isolated. B cells were separated from $\mathrm{T}$ cells by negative selection of $\mathrm{B}$ cells using magnetic beads coated with anti-CD3 antibodies and negative selection of $\mathrm{T}$ cells using anti-CD19 (Dynal AS, Oslo, Norway). To verify the purity of these two cell populations, flow cytometric analysis was used.

The isolated B cells were considered neoplastic. Patients' own T cells were chosen as the normal, negative controls, similar to previous publications (Gartenhaus et al, 1996). DNA was extracted from $\mathrm{B}$ and $\mathrm{T}$ cells (tumour and normal cells, respectively) using Puregene kit (Gentra Systems, Minneapolis, USA), according to the manufacturer's instructions.

\section{Microsatellite marker analysis}

Primer sequences at six different loci were selected from Genome Database (Table 1). P16, MLL and Leu1 are known to be involved in haematological tumours: (1) P16 is a tumour suppressor gene, which encodes an inhibitor of cyclin-dependent kinase 4 (CDK4). Binding of the product of P16 to CDK4 prevents progression through the cell cycle. Alterations of the P16 gene, like deletions, hypermethylation and mutations were reported in 30\% of transformed variants of non-Hodgkin's lymphoma (NHL). (2) $11 q 21-23$ is involved in translocations that are very common in AML and ALL. One of the genes described in 11q23 is MLL, which is rearranged with a variety of partners in haematological malignancies (Takeuchi et al, 1997, ; Webb et al, 1999). Deletions in 11q23 were also observed in B-CLL (Dohner et al, 2000). (3) Structural abnormalities in $13 q 14$ are very frequent in B-CLL (Fundia et al, 1998; Dohner et al, 2000). Rb1 is located in this region and was found to be involved in tumorigenesis. Recently, two novel candidate tumour suppressor genes Leu 1 and Leu2 were mapped to this region.

In addition, $h M L H-1, h M S H-2$ and $A P C$ were chosen. $h M L H-1$ and $h M S H-2$ encode DNA mismatch repair enzymes and are involved in both haematological and solid malignancies. The APC gene was selected mainly as a control. Despite possible involvement of APC gene in tumorigenesis of MALT lymphoma and gastric high-grade large B-cell lymphoma (Calvert et al, 1995; Starostik et al, 2000), this gene has no known role in the pathogenesis of this tumour.

The microsatellites within or closely located to the above loci were chosen (sequences are presented in Table 1). One end of each primer was synthesised and labelled by FAM (Mycrosynth, Balgach, Switzerland) and the opposite was synthesised by Sigma-Genosys (Cambridgeshire, UK). Microsatellite loci in genomic DNA were amplified by polymerase chain reaction (PCR) using Biometra Thermocycler (Whatman, Gottingen, Germany) in $15 \mu \mathrm{l}$ volume. The PCR mixture consisted of $1 \times$ PCR buffer (10 mM Tris-HCL, pH 8.3, $50 \mathrm{~mm} \mathrm{KCL,} 1.5 \mathrm{~mm} \mathrm{MgCl}_{2}$ ), $0.2 \mathrm{~mm}$ of each dNTP (Roche, Mannheim, Germany), 6 pmol of each primer and 1.5 units of Taq polymerase (Sigma, MO, USA). Both tumour and normal DNA were subjected to 36 cycles of PCR with automated temperature cycling programme as follows: denaturation at $94^{\circ} \mathrm{C}$ for $30 \mathrm{~s}$, annealing at $55^{\circ} \mathrm{C}$ for all primers except $\mathrm{P} 16\left(57.5^{\circ} \mathrm{C}\right)$ for $30 \mathrm{~s}$ and elongation at $72^{\circ} \mathrm{C}$ for $30 \mathrm{~s}$. Amplification was concluded with extension at $72^{\circ} \mathrm{C}$ for $30 \mathrm{~min}$ to avoid incorrect allele cells due to tendency of Taq DNA polymerase to add A base to $3^{\prime}$ end of DNA. This long extension promotes A addition to all the PCR products.

Fluorescent PCR products were subjected to electrophoresis on denaturing polyacrylamide gel and fractionated by Automated Fluorescent DNA Sequencer (ABI 377, PE Biosystems). The data were processed using GeneScan Analysis Software (Perkin Elmer, Foster City, CA, USA).

We used the common acceptable definitions of MSI and loss of heterozygosity (LOH) (Dietmaier et al, 1997). Microsatellite instability was defined as a change of any length due to either insertion or deletion of repeating units, in a microsatellite within tumour cells (B cells) compared to normal cells ( $\mathrm{T}$ cells). This was seen as novel peak/s in B cells DNA differing in size and location

Table I Microsatellite markers

\begin{tabular}{|c|c|c|c|c|}
\hline Locus/marker & Location & Repeat & Nearby located gene & Primer sequence \\
\hline D5S346 & $5 q 22-q 23$ & $(C A)_{26}$ & APC, distance $30-70 \mathrm{~kb}$ & $\begin{array}{l}\text { F-FAM ACTCACTCTAGTGATAAATCG } \\
\text { R-AGCAGATAAGACAGTATTACTAGTT }\end{array}$ \\
\hline D9SI7I & $9 p 21$ & $(C A)_{14}$ & PI6 & $\begin{array}{l}\text { F-FAM GCTAAGTGAACCTCATCTCTGTCT } \\
\text { R-GAGATCCTATTITTCTTGGGGC }\end{array}$ \\
\hline DIIS6I4 & | | q23 & $(\mathrm{A})_{13}(\mathrm{GAA})_{5}$ & MLL Intron 6 & $\begin{array}{l}\text { F-FAM CGCTGGTAATCCCAACACTT } \\
\text { R-ACCTGGGACTACACGCAACT }\end{array}$ \\
\hline AFMA30IWB5 & $|3 q| 4.3$ & $(C A)_{14}$ & Leul & $\begin{array}{l}\text { F-FAM TCAACATCACCTGTATTCAGCC } \\
\text { R-CGGCCTCCAAACACTAATTT }\end{array}$ \\
\hline
\end{tabular}


from T cells DNA (Figure 1). Unlike MSI, LOH was defined as loss of one of the pre-existing alleles in tumour cells compared to normal tissue (Figure 2). In this situation, one cannot easily discern whether this represents true LOH or MSI in which the shifted allele has comigrated with the remaining wild-type allele. These cases were defined as $\mathrm{LOH}$, although scoring results in this fashion would appear to bias the data in favour of $\mathrm{LOH}$ group.

RER positivity was defined as the finding of MSI in more than $30 \%$ of examined loci, as it commonly accepted (Boland et al, 1998).

\section{Statistical analysis}

Standard descriptive statistics, including means, standard deviations, ranges and frequency calculations were used to characterise the study group. For comparisons, a $\chi^{2}$ and Student's $t$-tests with two-sided type I error of 0.05 was used to assess statistical significance. In addition, a test for comparison of two proportions was used. $P$ less than 0.05 with $z$ more than 1.65 was considered as statistically significant.

\section{RESULTS}

A total of 26 patients with previously untreated B-CLL participated in the study. Of them, 16 patients were newly diagnosed B-CLL patients and the rest were previously untreated B-CLL patients who were at follow-up in the Department of Hematology of Meir Hospital.

Patients' characteristics are presented in Table 2. The study group included 10 women and 16 men with a mean age of 69.7 years (range, 45-86 years) and a mean leucocyte count of $60456 /$ $\mu \mathrm{l}$. In all, 16 patients had stage A CLL, six had stage B and five stage $\mathrm{C}$ (according to Binet's classification). Samples 4 and 27 were collected from the same patient after progression from stage B to C. According to their medical records, eight patients had additional malignancies in the past (Table 2), but none received chemo or radiotherapy for these tumours. All eight patients were at complete remision from these tumours at the time of the study.

Table 3 presents the results of microsatellite markers' analysis of the study group. Four patients (Gartenhaus et al, 1996; Tasak et al, 1996; Mark et al, 1998; Duval and Hamelin, 2002a, b) were found to be RER positive $(14.8 \%)$. The mean age and the mean leucocyte count were not significantly different from the patients without RER positivity $(P=0.1)$.

A higher prevalence of RER positivity was demonstrated in a subgroup of patients with additional malignancies in the past $(3 / 8$ RER positive patients) compared to patients without history of tumours $(1 / 19$ RER positive patients) $(P=0.031)$. No correlation was found between the prevalence of RER + and the type of additional malignancy. Similarly, RER positivity was more common at stage C (40\%), compared to stages A or B (12.5 and $0 \%$ respectively) $(P<0.05)$. There was no difference in the rate of RER positivity between stages $A$ and $B$.
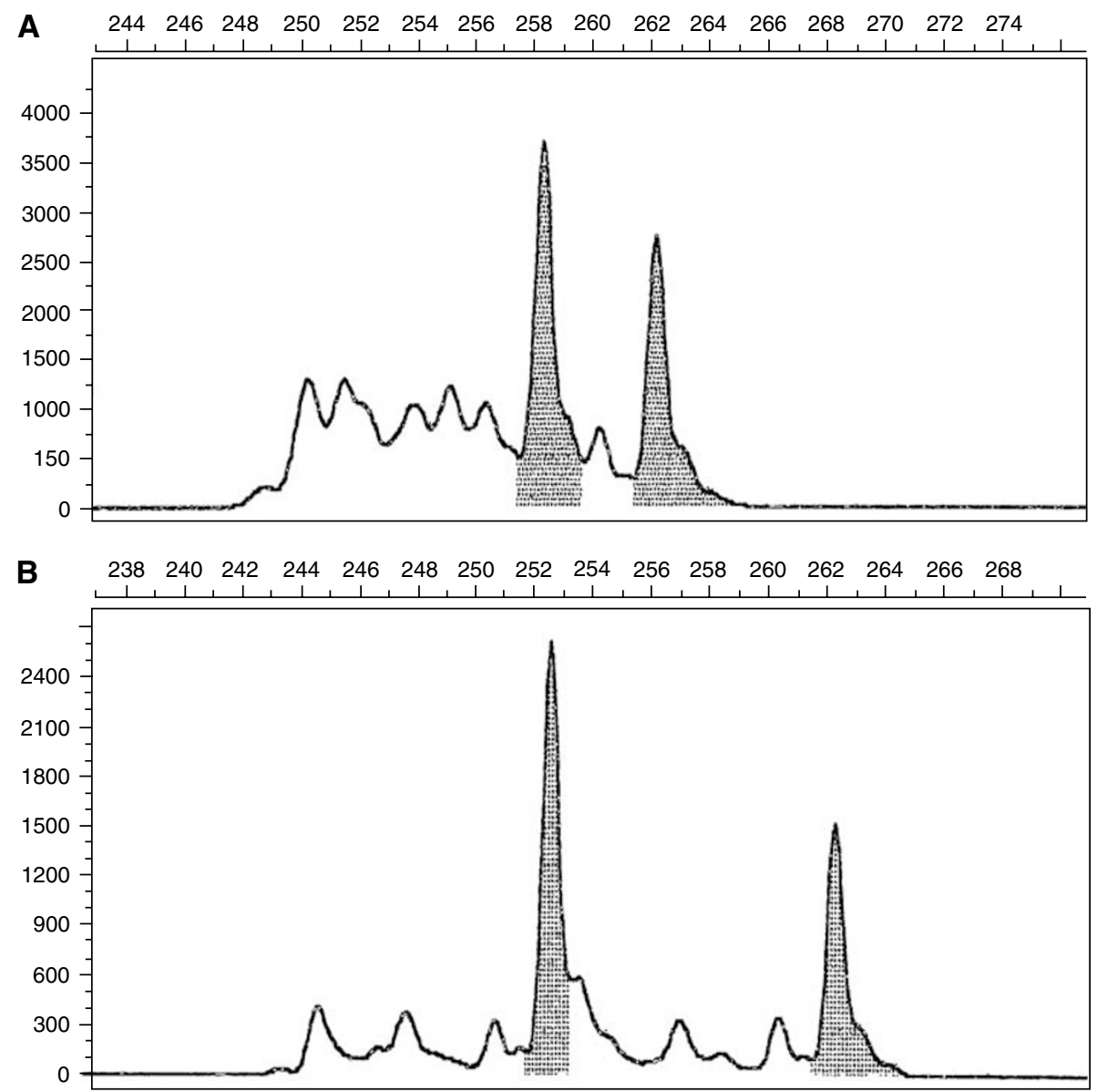

Figure I Representative allelic profile of microsatellite instability at $h M L H I$ locus. (A) T cells (normal cells). Horizontal - base pairs scale, vertical fluorescence scale. In the normal cells, the two major peaks are 258 and 262 base pairs long representing the two alleles of this microsatellite. (B) B cells (malignant cells). Horizontal - base pairs scale, vertical - fluorescence scale. In the malignant cells, the one of the alleles of the microsatellite is 262 base pairs long like in the normal cells, but the second one is 252 base pairs long (which is different from the allel of 258 base pairs). 
MSI in B-CLL

E Niv et al

A 192193194195196197198199200201202203204205206207208209210211

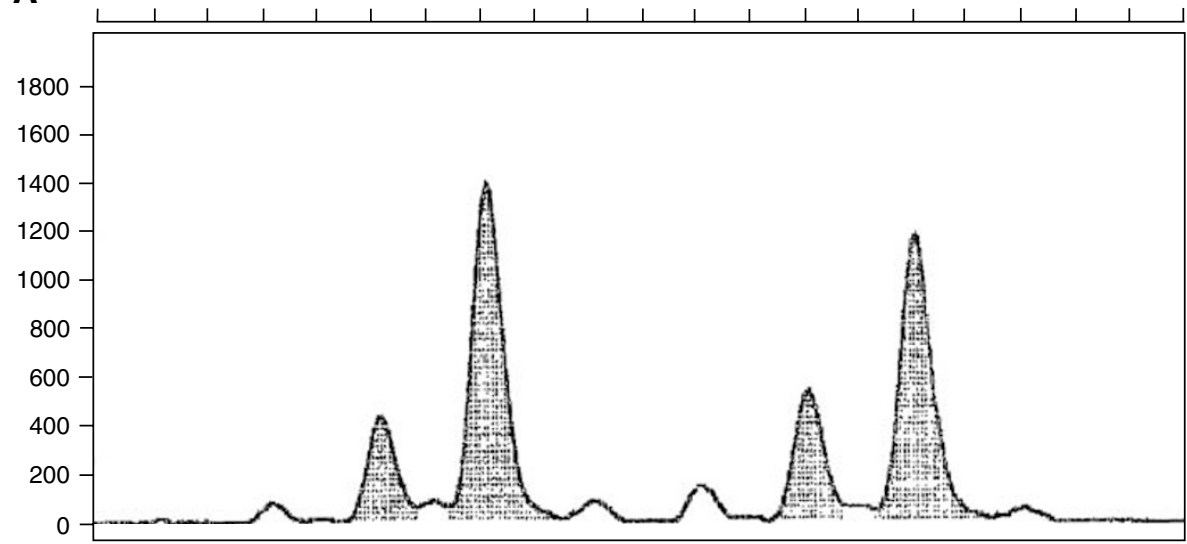

B 196197198199200201202203204205206207208209210211212213214215

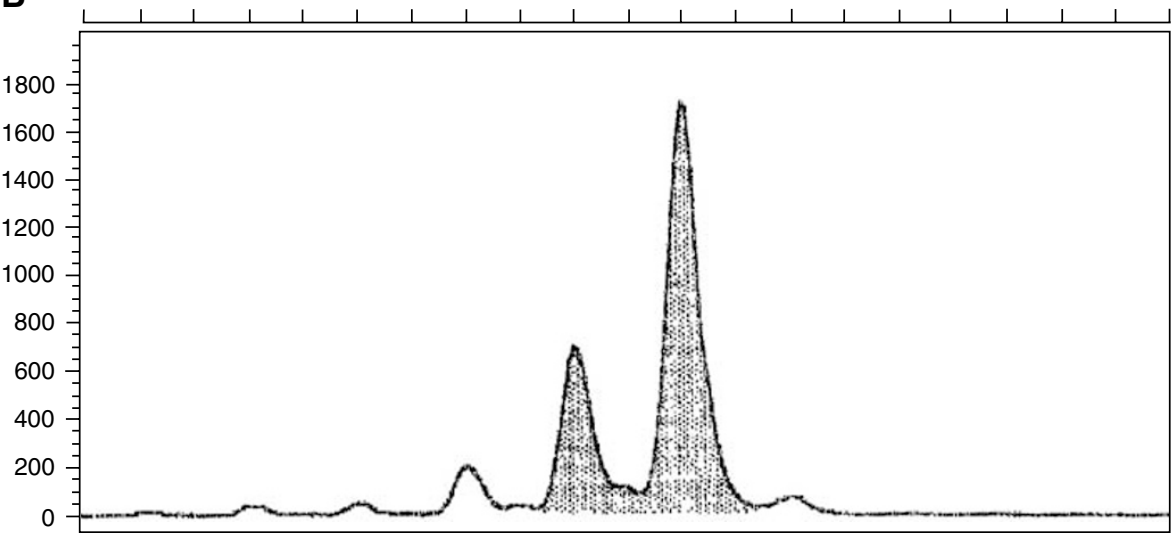

Figure 2 Representative allelic profile of loss of heterozygosity at Leul locus. (A) T cells (normal cells). Horizontal - base pairs scale, vertical fluorescence scale. In the normal cells, the two alleles of this microsatellite are 109 and 207 base pairs long. (B) B cells (malignant cells). Horizontal - base pairs scale, vertical - fluorescence scale. In the malignant cells the alleles of 109 disappeared and only the alleles of 207 base pairs remained.

Table 2 Clinical characteristics

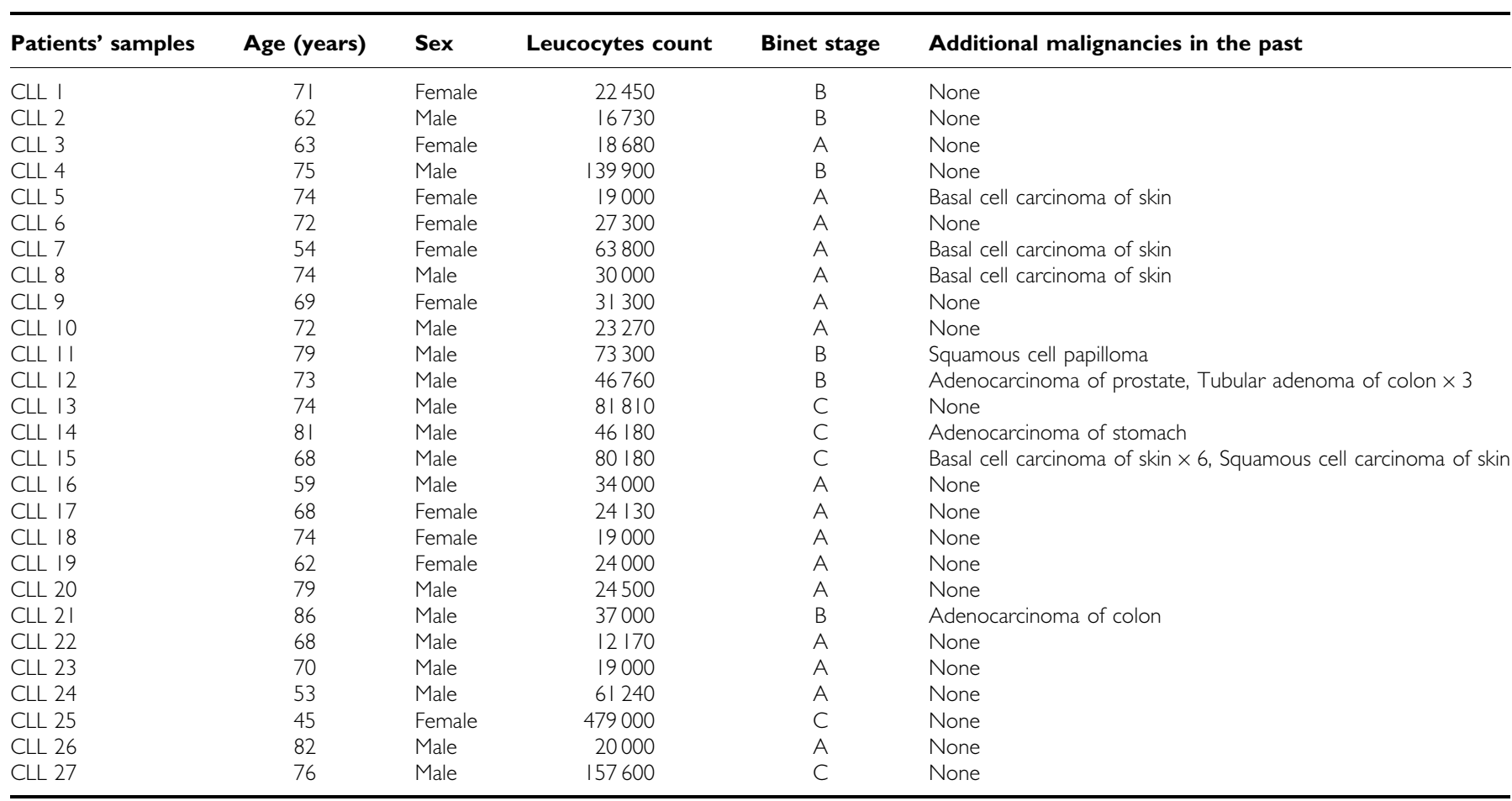


Table 3 Microsatellite analysis in the study group

\begin{tabular}{|c|c|c|c|c|c|c|}
\hline Patients' samples & Leul & MLL & APC & $\mathrm{MSH} 2$ & PI6 & MLH I \\
\hline CLL I & Stable & Stable & Stable & Stable & MSI & Stable \\
\hline CLL 2 & Stable & Stable & Stable & Stable & Stable & Stable \\
\hline CLL 3 & Stable & Stable & Stable & Stable & Stable & Stable \\
\hline CLL 4 & Stable & Stable & Stable & Stable & Stable & Stable \\
\hline CLL 5 & MSI & MSI & LOH & Stable & MSI & Stable \\
\hline CLL 6 & Stable & Stable & Stable & Stable & Stable & Stable \\
\hline CLL 7 & Stable & Stable & Stable & Stable & Stable & Stable \\
\hline CLL 8 & Stable & Stable & Stable & Stable & Stable & Stable \\
\hline CLL 9 & Stable & Stable & Stable & Stable & Stable & Stable \\
\hline CLL 10 & Stable & Stable & Stable & Stable & Stable & Stable \\
\hline CLL I I & LOH & Stable & Stable & Stable & Stable & Stable \\
\hline CLL 12 & Stable & MSI & Stable & Stable & Stable & Stable \\
\hline CLL 13 & Stable & Stable & Stable & Stable & Stable & Stable \\
\hline CLL I4 & MSI & MSI & MSI & MSI & Stable & MSI \\
\hline CLL I 5 & MSI & MSI & MSI & MSI & Stable & MSI \\
\hline CLL 16 & Stable & Stable & Stable & Stable & Stable & LOH \\
\hline CLL I 7 & Stable & Stable & Stable & Stable & Stable & MSI \\
\hline CLL 18 & Stable & Stable & Stable & Stable & Stable & Stable \\
\hline CLL 19 & LOH & MSI & Stable & Stable & Stable & Stable \\
\hline CLL 20 & Stable & Stable & Stable & Stable & Stable & Stable \\
\hline CLL 2 I & Stable & Stable & Stable & MSI & Stable & LOH \\
\hline CLL 22 & Stable & Stable & Stable & Stable & Stable & LOH \\
\hline CLL 23 & Stable & Stable & Stable & Stable & Stable & LOH \\
\hline CLL 24 & Stable & MSI & Stable & Stable & Stable & MSI \\
\hline CLL 25 & Stable & Stable & Stable & Stable & $\mathrm{MSI}$ & Stable \\
\hline CLL 26 & Stable & Stable & Stable & Stable & Stable & Stable \\
\hline CLL 27 & Stable & Stable & MSI & LOH & Stable & LOH \\
\hline
\end{tabular}

Bold is used for patients' samples with RER+/MSI in more than 30\% of examined loci.

Table 3 highlights additional interesting observations. First, the progression of instability from stage B (sample 4) to stage C (sample 27). Second, the marked instability of samples 14 and 15. These patients represented the MSI-H phenotype (instability at more than $40 \%$ of the loci examined). These patients also had a positive association with additional malignancies.

The frequency of MSI in each microsatellite locus was evaluated. Microsatellite instability was found at Leu1 locus in three out of $27(11.1 \%)$ of samples, at $M L L$ in six out of $27(22.2 \%)$, at $A P C$ in three out of $27(11.1 \%)$, at $M S H 2$ in three out $27(11.1 \%)$, at P16 in three out 27 (11.1\%), at MLH1 in four out $27(14.8 \%)$. In general, the rate of MSI at the examined loci was quite similar. Microsatellite instability in MLL locus was a little higher than in other loci, but it had no statistical significance $(P=0.47)$. $A P C$ locus, which is considered to be unstable mostly in solid tumours, had a similar rate of instability to other loci in the current study.

\section{DISCUSSION}

The present study has some unique features since we tested a relatively big group of previously untreated CLL for MSI in specific loci, which are involved in the pathogenesis of B-cell malignancies or encode for DNA mismatch repair enzymes. We also applied the GeneScan Analysis Software, which is considered the most precise method of microsatellite's analysis. We found RER-positivity rate of $14.8 \%$ in B-CLL. A significantly larger proportion of patients with stage $C$ exhibited RER positivity than those with stages A or B. Also higher prevalence of RER positivity was demonstrated a group of patients with additional malignancies in the past. The frequency of MSI at different loci was similar.

Previous studies on MSI in B-CLL reported much lower prevalence of RER positivity. For example, Sanz-Vaque et al (2001) found MSI-low in 3/24 (13\%) cases with B-CLL and no RER + at all. Gartenhaus et al (1996) identified a mutator phenotype in $7 \%(2 / 29)$ of the cases studied. Volpe et al (1996) also determined very low frequency of MSI among chronic lymphoproliferative disorders. An analysis of these studies reveals that the MSI was examined in wide variety of genomic loci, which were arbitrarily selected. In addition, loci tested in these studies are known to be unstable in solid but not in haematological malignancies.

A study of special interest is the study of Novak et al (2002), which performed an analysis of 400 microsatellite markers for instability in 46 patients with B-CLL. They found 41 novel allels in 22 patients (range 1-22 markers per patient). These results suggest very low frequency of MSI in B-CLL. However, the examined loci were selected arbitrarily; the study group included previously treated by chemotherapy along with untreated patients. In addition, the analysis of MSI was performed by comparison of mononuclear with polymorphonuclear cells, which were considered as tumour and normal cells respectively, presuming that most of mononuclear cells are B cells. Gartenhaus et al (1996) demonstrated that $\mathrm{B}$ and $\mathrm{T}$ cells are different genetically and that comparison of PCR products of microsatellite loci allows to diagnose MSI. For this reason, in our study a separation of these two kinds of cells was performed.

Only one study examined MSI at chromosomal breakpoint cluster regions specific to haematological malignancies (Pabst et al, 1996). In contrast to our findings, they found a low frequency of MSI: of 36 patients with B-CLL only one had RER $+(2.8 \%)$. The higher rate of genomic instability and RER positivity in our study probably reflects the careful selection of a homogenous group of previously untreated CLL patients, meticulous selection of the tested loci and the use of very sensitive and specific modern method of Genescan Analysis for MSI detection.

The finding of higher frequency of instability in some microsatellite loci than in other loci is not surprising. This was already demonstrated on the model of hereditary nonpolyposis colorectal cancer. A list of hundreds of microsatellites was tested and a panel of five microsatellites was chosen as those with most common instability (Boland et al, 1998). Thus, an individual panel of microsatellites relevant to each malignancy should be composed 
and proximity to genomic loci, which are involved in the pathogenesis of specific tumours, should be considered.

Our assumption about higher rate of MSI in meticulously selected genetic loci received a strong support recently by 'Real Common Target genes model' (Duval et al, 2002; Duval and Hamelin, 2002a, b; Woerner et al, 2003). According to this model, sets of few specific genes with high rate of mutations in different mismatch repair-deficient human cancers were identified. So far, this model was constructed only for colorectal, gastric and endometrial carcinomas. In order to develop such models for other tumours, data about MSI in different genetic loci of different tumours must be collected.

As mentioned above, the frequency of MSI in different selected loci in our study was quite similar. This is explained by meticulous selection of the tested loci with high probability of instability. However, surprisingly, the frequency of MSI in microsatellite near APC gene, which was selected mainly as a control, was high too. This finding may be explained by limited existing data about MSI in this gene. $A P C$ gene itself contains no microsatellite. In most previous studies about MSI in B-CLL, APC gene was not selected at all or different closely located microsatellites were tested.

Another important issue is an increase of instability upon the progression of CLL as was demonstrated by much higher rate of RER in stage $\mathrm{C}$ in comparison with stages $\mathrm{A}$ or $\mathrm{B}$ and an increase of instability in a patient upon disease progression. This finding is supported by a recently published study of Fulop et al (2003), who reported a high rate of MSI upon Richter's transformation of patients with B-CLL. It suggests that a defect in the DNA mismatch repair mechanism and progressive accumulation of replication errors have an important role in tumour biology of B-CLL.
Unfortunately, the number of patients with advanced stage in our study group was small, because only previously untreated patients were included. In addition, the study period was relatively short for B-CLL (1 year) and only one patient progressed to the higher stage. Thus, large long-term prospective studies are needed to evaluate the correlation between MSI status and clinical course of B-CLL.

Additional prominent finding in the study is a high prevalence of RER positivity in group of patients with additional malignancies in the past. This cannot be explained by the effect of chemotherapy, since our patients were untreated. This phenomenon was also demonstrated by Ericson et al (2003) on basis of MSI analysis in individuals with multiple primary malignancies. In this study, MSI was identified in 63/154 (41\%) tumours with a MSI-high pattern in 59 tumours. Immunohistochemical staining for DNA mismatch repair enzymes ( $M L H 1$ and $M S H 2)$ in the examined tumours demonstrated a very high frequency of expression loss. Thus, the phenomenon of development multiple tumours during lifetime may reflect a profound defect in DNA mismatch repair mechanism.

In summary, our study demonstrated that MSI might have a more prominent role in the pathogenesis of B-CLL than that has been reported. This may result from a selection of microsatellite markers adjacent to chromosomal loci, which are involved in B-cell malignancies. These findings support the 'Real Common Target genes' theory of high MSI in specific genes that are involved in specific tumours. Additional important observations were the trend for more instability with the progression of B-CLL and the high rate of RER positivity in patients with additional tumours in the past.

\section{REFERENCES}

Boland CR, Thibodeau SN, Hamilton SR, Sidransky D, Eshleman JR, Burt RW, Meltzer SJ, Rodriguez-Bigas MA, Fodde R, Ranzani GN, Srivastava S (1998) A national cancer institute workshop on microsatellite instability for cancer detection and familial predisposition: development of international criteria for the determination of microsatellite instability in colorectal cancer. Cancer Res 58: 5248-5257

Calvert R, Randerson J, Evans P, Cawkwell L, Lewis F, Dixon MF, Jack A, Owen R, Shiach C, Morgan GJ (1995) Genetic abnormalities during transition from Helicobacter-pylori-associated gastritis to low-grade MALToma. Lancet 345: 26-27

Dietmaier W, Wallinger S, Bocker T, Kullmann F, Fishel R, Ruschoff J (1997) Diagnostic microsatellite instability: definition and correlation with mismatch repair protein expression. Cancer Res 57: 4749-4756

Dohner H, Stilgenbauer S, Benner A, Leupolt E, Krober A, Bullinger L, Dohner K, Bentz M, Lichter P (2000) Genomic aberrations and survival in chronic lymphocytic leukemia. N Engl J Med 343: 1910-1915

Duval A, Hamelin R (2002a) Genetic instability in human mismatch repair deficient cancers. Ann Genet 45: 71-75

Duval A, Hamelin R (2002b) Mutations at coding repeat sequences in mismatch repair-deficient human cancers: toward a new concept of target genes for instability. Cancer Res 62: 2447-2454

Duval A, Reperant M, Hamelin R (2002) Comparative analysis of mutation frequency of coding and noncoding short mononucleotide repeats in mismatch repair deficient colorectal cancers. Oncogene 21(52): $8062-$ 8066

Ericson K, Halvarsson B, Nagel J, Rambech E, Planck M, Piotrowska Z, Olsson H, Nilbert M (2003) Defective mismatch-repair in patients with multiple primary tumors including colorectal cancers. Eur J Cancer 39: $240-248$

Fulop Z, Csernus B, Timar B, Szepesi A, Matolcsy A (2003) Microsatellite instability and hMLH1 promoter hypermethylation in Richter's transformation of chronic lymphocytic leukemia. Leukemia 17: 411-415

Fundia A, Giere I, Larripa I, Slavutsky I (1998) Spontaneous breakage and fragile site expression in chronic lymphocytic leukemia. Cancer Genet Cytogenet 103: $144-148$
Gartenhaus R, Johns MM, Wang P, Rai K, Sidransky D (1996) Mutator phenotype in a subset of chronic lymphocytic leukemia. Blood 87: $38-41$

Mark Z, Toren A, Amariglio N, Schiby G, Brok-Simini F, Rechavi G (1998) Instability of nucleotide repeats in Hodgkin's disease. Am J Hematol 57: $148-152$

Montserrat E, Bosch F, Rozman C (1997) B-cell chronic lymphocytic leukemia: recent progress in biology, diagnosis, and therapy. Ann Oncol 8(Suppl): S93-S101

Novak U, Leibundgut EO, Hager J, Muhlematter D, Jotterand M, Besse C, Leupin N, Ratschiller D, Papp J, Kearsey G, Aebi S, Graber H, Jaggi R, Luthi JM, Meyer-Monard S, Lathrop M, Tobler A, Fey MF (2002) A highresolution allelotype of B-cell chronic lymphocytic leukemia (B-CLL). Blood 100: 1787 - 1794

Pabst T, Schwaller J, Bellomo MJ, Oestreicher M, Muhlematter D, Tichelli A, Tobler A, Fey MF (1996) Frequent clonal loss of heterozygosity but scarcity of microsatellite instability at chromosomal breakpoint cluster regions in adult leukemias. Blood 88: 1026-1034

Peltomaki P, Vasen HF (1997) Mutations predisposing to hereditary nonpolyposis colorectal cancer: database and results of a collaborative study. The International Collaborative group on Hereditary Nonpolyposis Colorectal Cancer. Gatroenterol 113: $1146-1158$

Randerson J, Cawkwell L, Jack A, Child JA, Lewis F, Hall N, Johnson P, Evans P, Barrans S, Morgan GJ (1996) Microsatellite instability in follicle centre cell lymphoma. Br J Hematol 93: 160-162

Rimsza LM, Kopecky KJ, Ruschulte J, Chen IM, Slovak ML, Karanes C, Godwin J, List A, Willman CL (2000) Microsatellite instability is not a defining genetic feature of acute myeloid leukemogenesis in adults: results of a retrospective study of 132 patients and review of the literature. Leukemia 14: $1044-1051$

Samowitz WS, Slattery ML, Potter JD, Leppert MF (1999) BAT-26 and BAT40 instability in colorectal adenomas and carcinomas and germline polymorphism. Am J Pathol 154: $1637-1641$

Sanz-Vaque L, Colomer D, Bosch F, Lopez-Guillermo A, Dreyling MH, Bosch F, Montserrat E, Campo E (2001) Microsatellite instability analysis 
MSI in B-CLL

E Niv et al

in typical and progressed mantle cell lymphoma and B-cell chronic lymphocytic leukemia. Haematologica 86: $181-186$

Starostik P, Greiner A, Schultz A, Zettl A, Peters K, Rosenwald A, Kolve M, Muller-Hermelink HK (2000) Genetic abrrations common in gastric high-grade large B-cell lymphoma. Blood 95: 1180-1187

Stone JG, Tomlinson IPM, Houlson RS (2000) Optimizing methods for determining RER status in colorectal cancers. Cancer Lett 149: 15-20

Takeuchi S, Cho SK, Seriu T, Koike M, Bartram CR, Reiter A, Schrappe M, Takeuchi C, Taguchi H, Koeffler HP (1999) Identification of three distinct regions of deletion on the long arm of chromosome 11 in childhood acute lymphoblastic leukemia. Oncogene 56: 2171-2177

Takeuchi S, Seriu T, Tasaka T, Koike M, Cho SK, Park S, Slater J, Mufti I, Hatta Y, Miyoshi I, Bartram CR, Koeffler HP (1997) Microsatellite instability and other molecular abnormalities in childhood acute lymphoblastic leukaemia. Br J Haematol 98: 134-139

Tasak T, Lee S, Spira S, Takeuchi S, Hatta Y, Nagai M, Takahara J, Koeffler HP (1996) Infrequent microsatellite instability during the evolution of the myelodysplastic syndrome to acute myelocytic leukemia. Leukemia Res 20: $113-117$

Toft NJ, Arends MJ (1998) DNA mismatch repair and colorectal cancer. J Pathol 185: 123-129

Volpe G, Gamberi B, Pastore C, Roetto A, Pautasso M, Parvis G, Camaschella C, Mazza U, Saglio G, Gaidano G (1996) Analysis of microsatellite instability in chronic lymphoproliferative disorders. Ann Hematol 72: $67-71$

Webb JC, Golovleva I, Simpkins AH, Kempski H, Reeves B, Sturt N, Chessells JM, Brickell PM (1999) Loss of heterozygosity and microsatellite instability at the MLL locus are common in childhood acute leukemia, but not in infant acute leukemia. Blood 94: $283-290$

Woerner SM, Benner A, Sutter C, Schiller M, Yuan YP, Keller G, Bork P, Doeberitz MK, Gebert JF (2003) Pathogenesis of DNA repair-deficient cancers: a statistical meta-analysis of putative Real Common Target genes. Oncogene 22: 2226-2235 